\title{
Obituary of Professor Chieh-Su Hsu
}

\author{
Henryk Flashner · Jian-Qiao Sun
}

Published online: 26 August 2014

(C) Springer-Verlag Berlin Heidelberg 2014

C. S. Hsu, one of the foremost researchers in the area of dynamics and vibrations passed away on July 22, 2014 at the age of 92 in Cupertino, California.

C. S. Hsu graduated in 1945 from the National Institute of Technology, Chungking, China. After working from 1946 to 1947 at Shanghai Naval Dockyard and Engineering Works, he attended Stanford University where he earned a master's degree in 1948 and a PhD in 1950, respectively. Between 1951 and 1955, he worked as an Engineer for IBM Corporation in Poughkeepsie, New York. He was Associate Professor at University of Toledo, Toledo, Ohio between 1955 and 1958. Professor Hsu moved to the University California, Berkeley where he was Associate Professor 1958-1964 and Professor 1964-1991. Until his death he held the title of Professor Emeritus at UC Berkeley.

Prof. C. S. Hsu devoted more than half a century to vibration theory and practice while leading Berkeley's dynamics group from the 1960s until his retirement. His research spanned across virtually every important area of nonlinear dynamical systems analysis and applied mechanics. His early research interest was in the area of elasticity and continuum mechanics. Parametric excitation was the focus of Professor Hsu's research in the 1960s. Dynamic stability of arches, including snap-through instabilities under various loading, equilibrium configurations and arches on elastic foundations were other topics of his research in the late 1960s. He was

\section{H. Flashner}

Department of Aerospace and Mechanical Engineering, University of Southern California, Los Angeles, CA 90089-1453, USA

e-mail: hflashne@usc.edu

J.-Q. Sun $(\bowtie)$

School of Engineering, University of California, Merced 5200 N. Lake Road, Merced, CA 95343, USA

e-mail: jqsun@ucmerced.edu

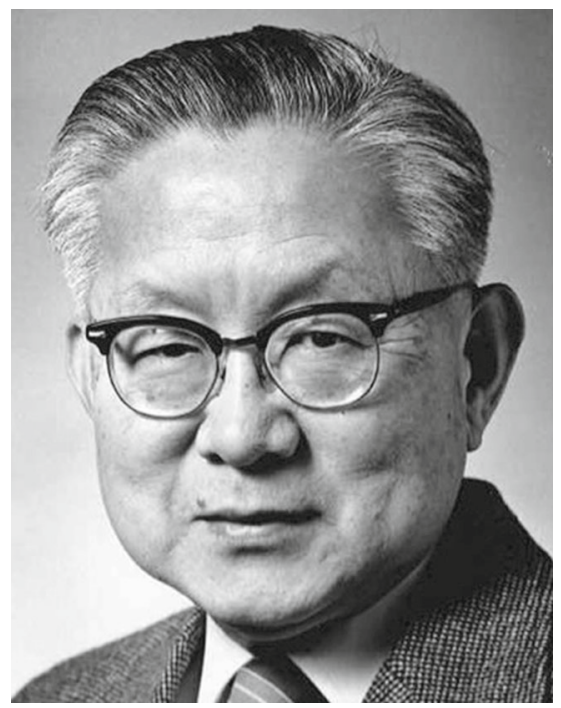

the first ever to create the stability chart for delayed oscillators in 1966. Professor Hsu returned to parametric excitation in the 1970s to study problems of parametric instability of continuous and discrete nonlinear dynamic systems using Lyapunov methods, impulsive excitations, limit cycle responses and combined forced and parametric excitation. From the late 1970's through the 1990's, Hsu greatest attention was focused on point-to-point and cell-to-cell mapping of nonlinear dynamic systems. His first works were on the theory of point-to-point mapping of global dynamic system response including introducing indexes in the stability predictions for systems of any order. Cell-to-cell mappings soon followed with algorithms for determining global responses and periodicity of higher order systems. Hsu introduced probabilistic theory based on the cell-state space concepts, identified singularities in finite dimensional cell functions and the associated index theory and located their zeros. He returned to 
parametric excitation analyses using the cell space theory, as well as limit cycles, domains of attraction, and ventured into optimal control theory based on the cell state space concepts. He extended the basic theory and applications of cell-state mapping methods to bifurcation theory, random vibration, piece-wise linear systems, fuzzy uncertainties, stochastic systems, internal resonances and other areas. These developments are summarized in Hsu's highly regarded treatise, Cellto-Cell Mapping-A Method of Global Analysis of Nonlinear Systems, which was published by Springer-Verlag Applied Mathematical Sciences Series in 1987. It remains the bible for cell-to-cell mapping and stands alone in the dynamics literature.

At UC Berkeley Professor Hsu earned a reputation as a brilliant lecturer and outstanding educator. He was known to convey his thoughts with uncommon clarity, distilled each topic to its essence, and knew how to engage students in lively discussions both in and outside the classroom. Professor Hsu has taught a premier graduate course sequence in dynamics and vibrations that included linear vibration theory, random vibrations, nonlinear oscillations, and elastic stability. Because of his great popularity as a teacher, the number of students he taught during his career must be measured in the thousands. The impact that his teaching has made on generations of researchers in the area of dynamics and vibrations is therefore tremendous and will be felt for many years to come.

The exceptional achievements of Professor Hsu as a researcher and an educator earned him many honors and awards. He was elected to the U.S. National Academy of
Engineering in 1988 and to the Chinese Academia Sinica in 1990. He was a Fellow of American Society of Mechanical Engineers, and a Fellow of the American Academy of Mechanics. Professor Hsu received the most prestigious awards of the American Society of Mechanical Engineers in the area of dynamics and vibrations: the American Society Mechanical Engineers Centennial Award in 1980, the N.O. Myklestad in 1995 and the J. P. Den Hartog award in 2011. He also won the prestigious Alexander von Humboldt Senior U.S. Scientist Award, the Guggenheim Fellowship and the Miller Research Professorship at Berkeley. He has served on the Scientific Advisory Board of the Alexander von Humboldt Foundation and the U.S. National Committee on Theoretical and Applied Mechanics. Professor Hsu served as the Technical Editor of the Journal of Applied Mechanics from 1976 to 1982 . He was also on editorial boards of the leading journals in the area of dynamics and vibrations such Acta Mechanica, International Journal of Nonlinear Mechanics, Journal of Optimization Theory, and Bifurcation and Chaos in Applied Science and Engineering.

Professor C. S. Hsu was, without a doubt, one of the most influential members of the dynamics and vibration community. His contributions, both in education and in research, are enormous and have touched every researcher and engineer working in the field.

Professor Hsu will be dearly missed by his students, colleagues, friends and family! 